\title{
Indoor Air Quality Monitoring Using Infrastructure-Based Motion Detectors
}

\section{Hossein Motlagh, Naser}

IEEE

2019

Hossein Motlagh , N , Zaidan , M , Lagerspetz , E , Varjonen , S , Toivonen , J , Mineraud , J , Rebeiro-Hargrave , A , Siekkinen, M , Hussein , T, Nurmi , P \& Tarkoma , S 2019 , Indoor Air Quality Monitoring Using Infrastructure-Based Motion Detectors . in Proceedings : 2019 IEEE 17th International Conference on Industrial Informatics (INDIN) . vol. 1, IEEE International Conference on Industrial Informatics (INDIN) , vol. 1 , IEEE , pp. 902-907 , 17th International Conference on Industrial Informatics (INDIN), Helsinki , Finland , 22/07/2019 . https://doi.org/10.1109/I

http://hdl.handle.net/10138/310796

https://doi.org/10.1109/INDIN41052.2019.8972332

acceptedVersion

Downloaded from Helda, University of Helsinki institutional repository.

This is an electronic reprint of the original article.

This reprint may differ from the original in pagination and typographic detail.

Please cite the original version. 


\title{
Indoor Air Quality Monitoring Using Infrastructure-Based Motion Detectors
}

\author{
Naser Hossein Motlagh $\dagger$, Martha Arbayani Zaidan $\ddagger$, Eemil Lagerspetz $\dagger$, Samu Varjonen $\dagger$, Juhani Toivonen $\dagger$, \\ Julien Mineraud $\dagger$, Andrew Rebeiro-Hargrave $\dagger$, Matti Siekkinen $\dagger$, Tareq Hussein $\ddagger$, Petteri Nurmi $\dagger$, and Sasu Tarkoma $\dagger$ \\ $\ddagger$ Institute for Atmospheric and Earth System Research (INAR), University of Helsinki, Finland \\ $\dagger$ Department of Computer Science, University of Helsinki, Finland \\ Emails: $\dagger, \ddagger$ firstname.lastname@ @elsinki.fi
}

\begin{abstract}
Poor indoor air quality is a significant burden to society that can cause health issues and decrease productivity. According to research, indoor air quality is intrinsically linked with human activity and mobility. Indeed, mobility is directly linked with transfer of small particles (e.g. $\left.\mathbf{P M}_{2.5}\right)$ and extent of activity affects production of $\mathrm{CO}_{2}$. Currently, however, estimation of indoor quality is difficult, requiring deployment of highly specialized sensing devices which need to be carefully placed and maintained. In this paper, we contribute by examining the suitability of infrastructure-based motion detectors for indoor air quality estimation. Such sensors are increasingly being deployed into smart environments, e.g., to control lighting and ventilation for energy management purposes. Being able to take advantage of these sensors would thus provide a cost-effective solution for indoor quality monitoring without need for deploying additional sensors. We perform a feasibility study considering measurements collected from a smart office environment having a dense deployment of motion detectors and correlating measurements obtained from motion detectors against air quality values. We consider two main pollutants, $\mathrm{PM}_{2.5}$ and $\mathrm{CO}_{2}$, and demonstrate that there indeed is a connection between extent of movement and $\mathrm{PM}_{2.5}$ concentration. However, for $\mathrm{CO}_{2}$, no relationship can be established, mostly due to difficulties in separating between people passing by and those residing long-term in the environment.
\end{abstract}

Index Terms-Indoor Air Quality, Low-Cost Sensors, Motion Detectors, and Pollution Measurement.

\section{INTRODUCTION}

Estimates suggest that each year four million premature deaths result from illnesses attributable to indoor air pollution [1]. This is further exacerbated by the fact that humans tend to spend more time indoors than outdoors [2]. Among different indoor pollutants, especially particulate matter $\mathrm{PM}_{2.5}$ and $\mathrm{CO}_{2}$ emissions are linked with health concerns [3], [4]. Besides ventilation, indoor air quality is intrinsically linked with human movements and activities as they distribute particulate matter from floor and other surfaces and result in faster $\mathrm{CO}_{2}$ production. Air pollution concentration differs across indoor environments depending on number of people using the space and extent of human activity. For example in a very high mobility environments, e.g., at an airport concentration of air pollution is usually high [5]. The health effects of the pollutants is influenced by the exposure the person stays in the

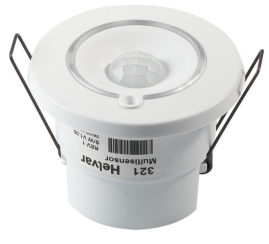

(a) Motion Detector.

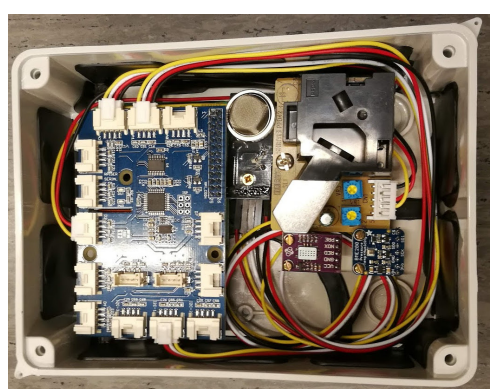

(b) Low-cost Sensor.
Fig. 1. The sensor devices used in the experiment.

building, in many cases people stay up 8 hours in the work spaces, oblivious to the changing air quality.

In this paper, we contribute by investigating the feasibility of infrastructure-based indoor motion sensors as proxy for assessing variations in indoor air quality. We build on opportunistic availability of motion detectors, which are increasingly used in smart buildings and offices, e.g., for energy management by helping to turn off lights or air conditioning during periods of sustained inactivity. Taking advantage of sensors deployed as part of existing infrastructure would thus provide a cost-effective solution that overcomes the need for deploying specialized sensing devices. As our main contribution, we present a feasibility study conducted in a smart office environment that seeks to establish a relationship between motion detector measurements and $\mathrm{CO}_{2}$ and $\mathrm{PM}_{2.5}$ concentration.

The results of our experiment highlight the relationship between number of movement and $\mathrm{PM}_{2.5}$ concentrations. For $\mathrm{PM}_{2.5}$, a strong relationship can be established. However, for $\mathrm{CO}_{2}$, no clear relationship can be established. Indeed, our results suggest that the formation of $\mathrm{PM}_{2.5}$ and $\mathrm{CO}_{2}$ concentration through movement is complex, due to chemical and physical processes and the impact of other unmeasured variables, e.g., VOCs, the quality of sensors, and characteristics of human activity within the space.

\section{RELATED WORK}

In the literature, there are studies that evaluate the feasibility of using low-cost sensors for air pollution detection [6] and 


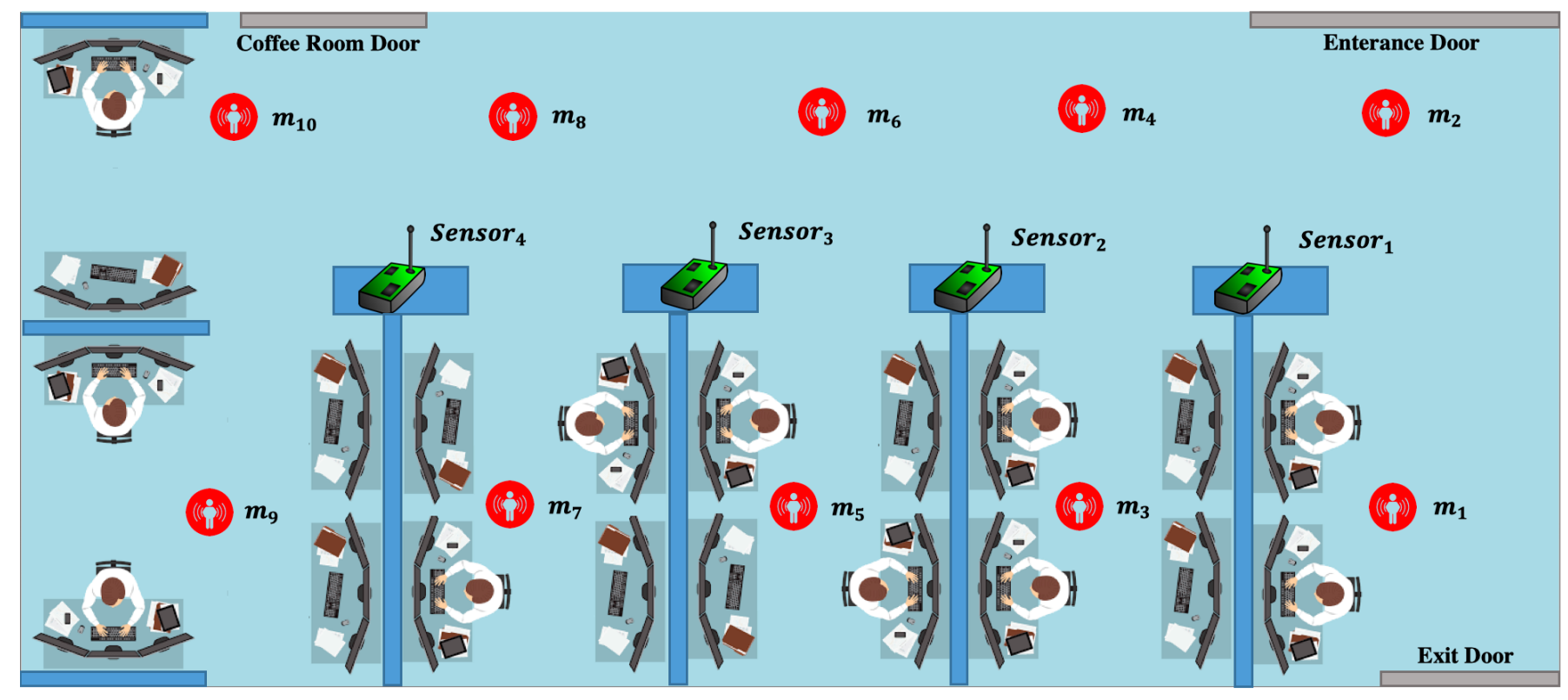

Fig. 2. The location of motion detectors $\left(m_{x}\right)$ and air quality sensors.

other studies that investigate the sources of air pollutants and the affect of human movement on generating or varying the airbone particles in the indoor environments. Coleman et al. [7] use inexpensive sensors to identify the source of pollutants in indoor air environment by measuring $\mathrm{CO}_{2}$. They highlight that the amount of pollutants correlates with both the occupancy near the sensors and the functioning of the ventilation systems. Arif et al. [8] use low-cost air quality sensors to measure $\mathrm{CO}_{2}$ concentration in a typical office room as well as a cinema theatre, highlighting relation of the level of $\mathrm{CO}_{2}$ with indoor human occupancy.

Qian et al. [9] investigates the resuspension of airborne particles indoors. Kubota et al. [10] study particle resuspension and redistribution caused by human foot motion, considering aerodynamic effects. This work illustrates the particle resuspension in real situations by particle flow visualizations with human foot tapping by a controlled experiment and highlights that the flooring, e.g. carpet, and the sole geometry of the shoe have important roles in causing transfer of pollutants. Alshitawi et al. [11] investigate resuspension concentration of contaminants due to human movement through a controlled experiment. The study evaluates the impact of three indoor walking speeds as slow, medium, and fast on the concentration of airborne particles at 5 different time intervals. The results demonstrate that walking speed has a significant impact on the concentration of the PM pollutants, i.e., the higher the speed, the higher the PM concentration.

Zhang et al. [12] investigate particle detachment, resuspension and transport due to indoor human walking numerically and experimentally. Their results illustrate that shoe bottom roughness, foot size, walking velocity, background velocity, foot stepping velocities, all affect particle resuspension rate from the floor and the corresponding particle concentrations in the indoor environment. Benabed et al. [13] study particle resuspension in the indoor environment due to human activity. Thus, the research uses an environmentally controlled experimental chamber to measure the particle matter (PM) using an optical particle counters (Grimm 1.108) and considering only the downward motion of the foot during the gait cycle. The research evaluate the walking-induced particles resuspension as a function of particle size and flooring type and concludes that the surface roughness improves particles resuspension.

To summarize, previous research has studied extensively mechanisms governing the process of indoor pollutant generation and transfer. Our research builds on this body of knowledge, looking at how to enable low-cost infrastructure-based air quality sensing using existing motion sensor deployments.

\section{Test EnVironment}

To perform the study, we chose UbiKampus which is an open working space at the University of Helsinki. Everyday, there are dozens of researchers who come to work in the space of $400 \mathrm{~m}^{2}$ and in addition there are many visitors who enter the space to use the meeting rooms or the coffee room. The working space is equipped with 10 motion detectors $m$ which are installed on the ceiling of the space with equal distances. Inside the space, there are fixed amount of working desks as well as shelves located at the middle of the space with equal distances. The shelves which are located right under and between the $m$ allow putting any light weight devices on them, where we used this possibility to place four low-cost air quality sensors on them with equal distances, under $m$ while between them. Fig. 1 shows the type of motion detector and the low-cost air quality sensor, we used in the experiment. The design of the space, location of the $m$ and the lowcost air quality sensors are also illustrated in Fig. 2. In the experiment, we collected motion data using the $m$ as described in Section III-A1, and indoor air pollutants (i.e., $\mathrm{CO}_{2}$ and 
$\mathrm{PM}_{2.5}$ ) using low-cost sensors as explained in Section III-A2, continuously from the $14^{\text {th }}$ February to the $18^{\text {th }}$ March, 2019.

\section{A. Sensors}

1) Motion Detectors: We used eight Helvar Digidim 321 motion detectors (as depicted in Fig. 1(a)) that are installed in light bars hanging from the ceiling at an height of $5.75 \mathrm{~m}$ according to Fig. 2. The detectors are part of a Mount Kelvin ${ }^{1}$ building automation system and we read and collect the motion events from an attached MQTT event stream. The building automation system suppresses future events from a sensor for 30 seconds after each transmitted event, which means that our measurements are also limited to one motion event per sensor every 30 seconds.

2) Air Quality Sensors: We used four low-cost air quality sensors built at the University of Helsinki. The picture of the low-cost sensor is shown in Fig. 1(b). The sensor is built on top of Raspberry Pi 3 model B. Most of gas sensing in the low-cost setup is handled with Metal Oxide semiconductor (MOX) sensors. MOX sensors can detect gas concentrations of pollutants such as $\mathrm{CO}, \mathrm{CO}_{2}, \mathrm{NO}_{2}, \mathrm{NO}_{\mathrm{x}}$ and $\mathrm{O}_{3}$. The sensors consists of an heating element and a semiconducting metal oxide sensing element. The heater warms the surface of the sensing element up to $300^{\circ}$ Celsius, which is then able to detect gases through a chemical reaction occurring on its surface. This reaction causes a change in the electrical conductivity of the sensing element, which can be monitored using an external circuit to measure the detected gas level [14].

MOX sensors are very low-cost and compact. They have long lifespan and are highly sensitive. They have also a short response time, which implies that the frequency at which the data is read from the sensors can be increased. PM was measured with a Shinyei Light scattering LSP sensor, which are small and low-cost and are used to detect Particulate Matter (PM). They are composed of an air inlet, a light sensor, and a light source, usually infrared or laser. When the air enters the sensor through the inlet, the light source is focused on a sensing point in which it hits the particles found in the air. An infrared LED is positioned in a forward angle with respect to a photodiode. Particles passing through the light beam scatter light, which generates a measurable signal in the sensor circuitry. The scattered light is focused on to the photodiode by a lens. The sensors may have light scattering focusing lens and a focusing lens also for the infrared light source. The sensor then produces a signal that allows estimating the number of particles in the air.

\section{B. Sensor Mapping}

To analyze the relation between the number of movements detected by $(m)$ and $\mathrm{PM}_{2.5}$ and $\mathrm{CO}_{2}$ variations, we performed

\footnotetext{
${ }^{1}$ https://mountkelvin.com
}
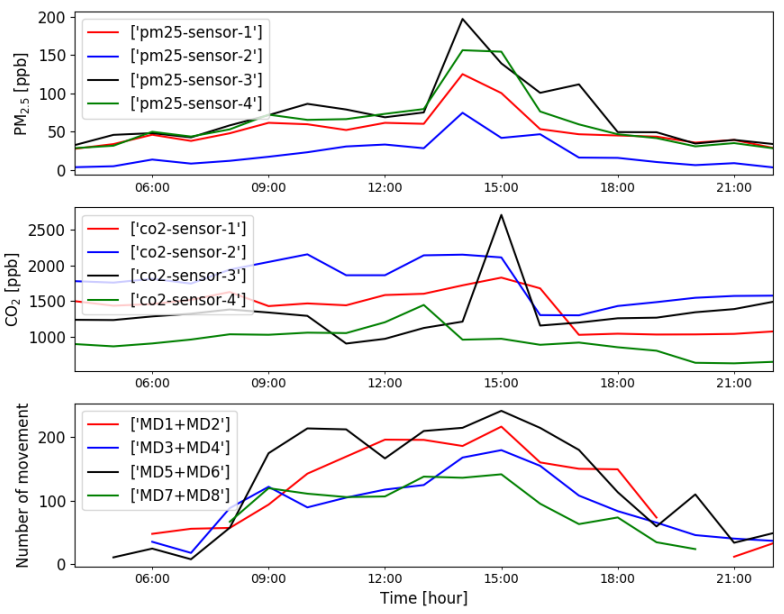

Fig. 3. The time-series data explaining the relationship between of number of movements with $\mathrm{PM}_{2.5}$ and $\mathrm{CO}_{2}$.

mapping $(\mathcal{M})$ between the two adjacent motion detectors $(m)$ and low-cost air quality sensors $(\mathcal{S})$, as shown in Fig. 2. To map the sensors, we use the mappings $(\mathcal{M})$ between the sensors and motion detectors, presented in Table I.

TABLE I

Different Mappings Between Sensors and Motion Detectors.

\begin{tabular}{ccccc}
\hline Sensors & $\mathcal{M}_{1}$ & $\mathcal{M}_{2}$ & $\mathcal{M}_{3}$ & $\mathcal{M}_{4}$ \\
\hline \hline $\mathcal{S}_{1}$ & $m_{1}$ & $m_{2}$ & $\left(m_{1}, m_{2}\right)$ & $\left(m_{2}, m_{4}\right)$ \\
\hline $\mathcal{S}_{2}$ & $m_{3}$ & $m_{4}$ & $\left(m_{3}, m_{4}\right)$ & $\left(m_{4}, m_{6}\right)$ \\
\hline $\mathcal{S}_{3}$ & $m_{5}$ & $m_{6}$ & $\left(m_{5}, m_{6}\right)$ & $\left(m_{6}, m_{8}\right)$ \\
\hline $\mathcal{S}_{4}$ & $m_{7}$ & $m_{8}$ & $\left(m_{7}, m_{8}\right)$ & $\left(m_{8}, m_{10}\right)$ \\
\hline
\end{tabular}

In the next section, we take the summation of number of movements detected by two adjacent $m$ near to the sensor $(\mathcal{S})$. Then, we study the relation between the number of movements and the pollutants $\mathrm{CO}_{2}$ and $\mathrm{PM}_{2.5}$ in the working space for the specified hours.

\section{DATA ANALYSis}

In the test environment, the low-cost sensors have been in operation since mid February 2019 whereas the motion detectors have just been activated since 8 March 2019. The data sampling also varies between three different sensors. For example, the sensors $\mathrm{CO}_{2}$ samples the data for about every 15 seconds until one minute whereas the sensors $\mathrm{PM}_{2.5}$ samples the data about every 30 seconds until two minutes. The motion detectors sense every movement in the room, thus, the data sampling is taken per every movement.

In order to consider the ventilation operation, we used experimental data from 8 until 18 March 2019, excluding weekends, which are 6 days. In addition, to find the common sampling frequency, the data is also resampled per every one hour by calculating the mean for $\mathrm{PM}_{2.5}$ and median for $\mathrm{CO}_{2}$. We took this approach, because the collected data contains 

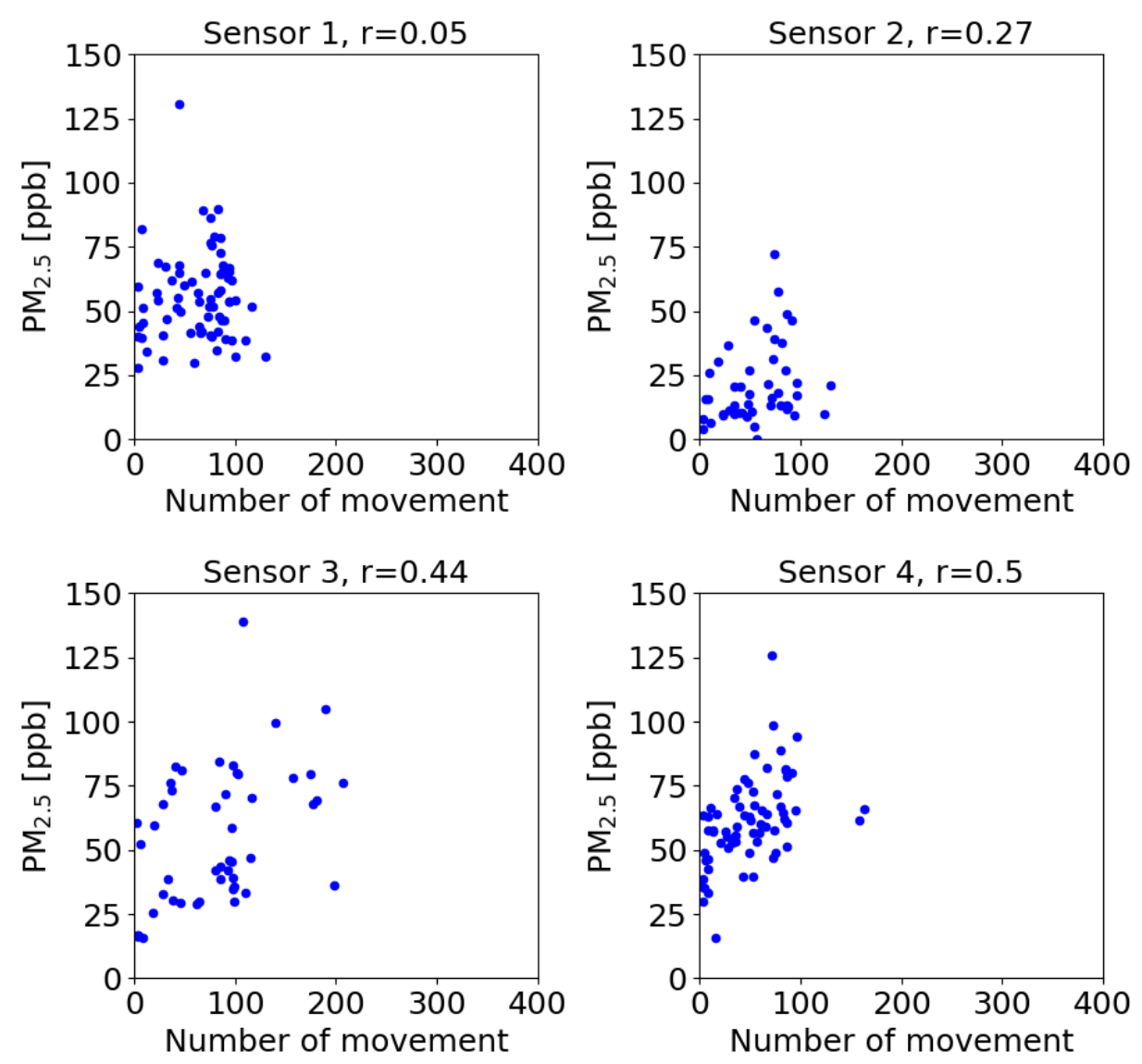

Fig. 4. The scatter plot between the number of movement and $\mathrm{PM}_{2.5}$ concentration obtained from all the sensor devices. The symbol $r$ in the Figure titles represents Pearson correlation coefficient.

some outliers, i.e. sometimes the concentration become suddenly too large. It is known that median is a measure of central tendency but offers the advantage of being very insensitive to the presence of outliers [15].

\section{A. Dataset}

Fig. 3 presents six days average concentration of $\mathrm{PM}_{2}$. 5 (top-plot) and $\mathrm{CO}_{2}$ (middle-plot) as well as the number of movements (bottom-plot). The figure demonstrates that the number of movement has mostly taken place between 06:00 and 22:00. This is almost in agreement with $\mathrm{PM}_{2}$. ${ }_{5}$ concentration for all sensors. The $\mathrm{CO}_{2}$ concentration also shows a slight increasing trend in the morning and dropping significantly around $16: 00$ and $18: 00$ in the afternoon. The reason stem from the operation time of the ventilation system as well as the decreasing number of researchers at the space starting from $16: 00$. However, although there is almost no motion after about 21:00, the concentration rises again until after mid-night. This anomaly trend takes place because the ventilation system operates from $06: 00$ until $19: 00$, resulting in trapped $\mathrm{CO}_{2}$ concentration in the room.

\section{B. Correlations With Different Sensor Combinations}

To study the effect of movement at different places of the open space, we considered different mappings $(\mathcal{M})$ between the sensors $(\mathcal{S})$ and the motion detectors, as shown in Table I. Then, as explained we calculated the mean for $\mathrm{PM}_{2.5}$ and median for $\mathrm{CO}_{2}$. Whereas, the Pearson correlation coefficients obtained between the number of movements, $\mathrm{PM}_{2.5}$ and $\mathrm{CO}_{2}$ are presented in Table II. Pearson correlation coefficient explains the degree of linear correlation between two variables [16] The higher Pearson correlation coefficient indicates that better mapping between low cost sensors and the motion detectors. It can be seen from the Table II that the best mapping from $\mathrm{PM}_{2.5}$ is $\mathcal{M}_{2}$ because the locations of the motion detectors of $2,4,6$ and 8 are closer the corresponding low-cost sensors. This area is also a walking path for people who are working on the office (see Fig. 2). Correlations of $\mathrm{CO}_{2}$ are higher overall for $S_{2}$, as that is roughly in the centre of the space where most people work. Also $S_{4}$, when taken to correspond to $m_{7}$, or both $m_{7}$ and $m_{8}$, gives reasonable correlations. $S_{2}$ and $S_{4}$ also see lower movement counts than $S_{1}$ and $S_{3}$ as we will see later in this paper. $S_{1}$ is close to the 

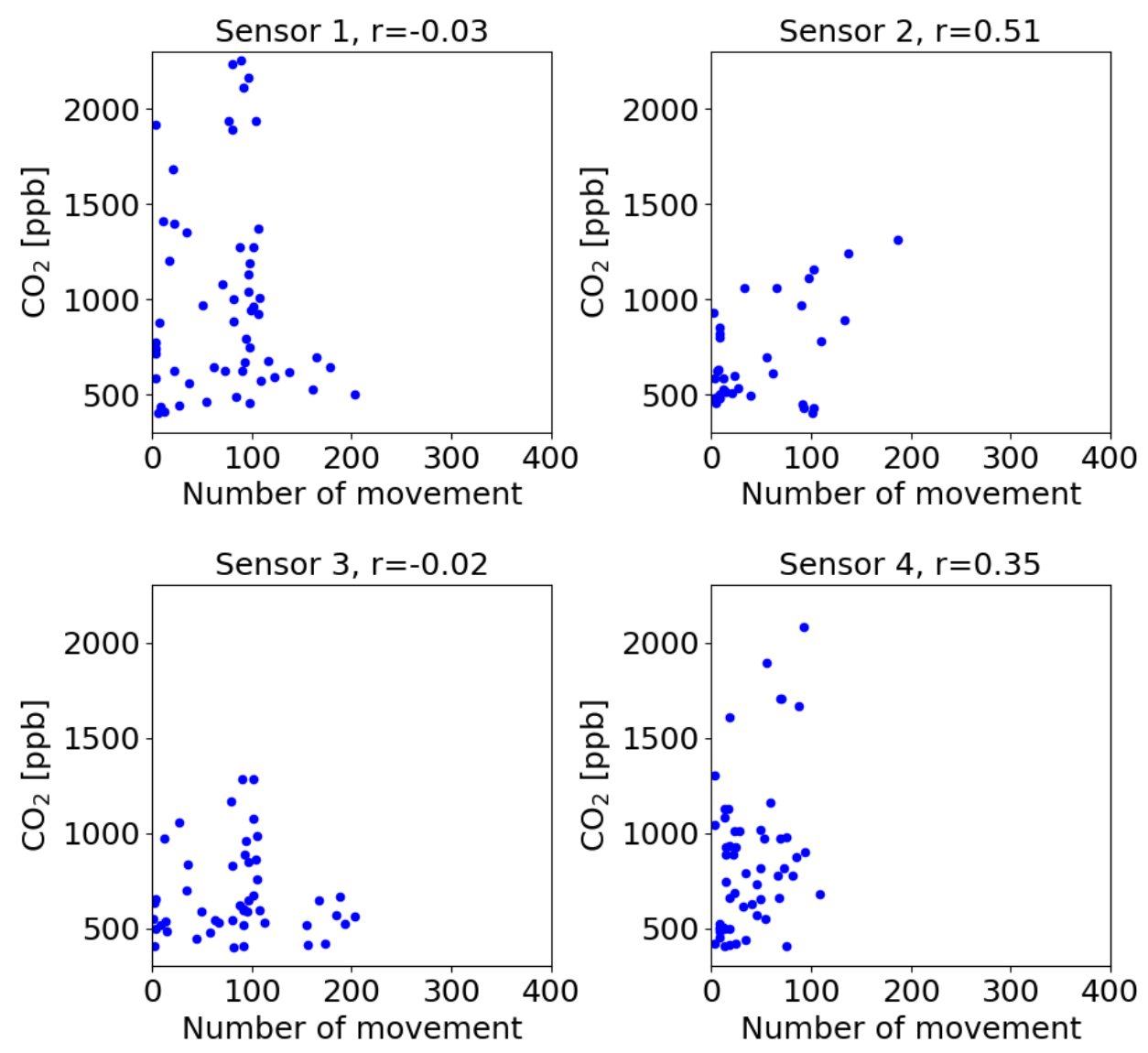

Fig. 5. The scatter plots between the number of movement and $\mathrm{CO}_{2}$ concentration obtained from all the sensor devices. The symbol $r$ in the Figure titles represents Pearson correlation coefficient.

entrance, and thus sees a higher amount of motion. Difference in motion may be one reason why $S_{3}$ that is more central to the space still sees less $\mathrm{CO}_{2}$ than $S_{2}$ and $S_{4}$.

\section{Sensing Air Quality with Motion Detectors}

In order to demonstrate how the number of movements inside the working space affects the levels of pollutants, from the Table I, we select the mappings $\mathcal{M}_{1}$ and $\mathcal{M}_{2}$ to scatter plot the variations of $\mathrm{CO}_{2}$ and $\mathrm{PM}_{2.5}$, respectively.

Fig. 4 presents the scatter plots between the number of movement and the $\mathrm{PM}_{2.5}$ concentration. The symbol $r$ is Pearson correlation coefficient. It can be seen that the sensors 3 and 4 of $\mathrm{PM}_{2.5}$ demonstrate reasonable linear correlation between number of movement and $\mathrm{PM}_{2.5}$ concentration, with $r=0.44$ and $r=0.5$, respectively. This indicates that when the number of movement increases, the $\mathrm{PM}_{2.5}$ concentration also tends to rise. However, the sensors 1 and 2 do not exhibit good correlation visually between these two variables, although the coefficient of sensor 2 is about 0.27 . Fig. 5 displays the scatter plots between the number of movement and the $\mathrm{CO}_{2}$ concentration. The sensor 1 and 3 do not exhibit
TABLE II

CORRELATION COEFFICIENTS $(r)$ BETWEEN THE NUMBER OF MOTION, $\mathrm{PM}_{2.5}$ AND $\mathrm{CO}_{2}$ ON DIFFERENT MAPPINGS AS PRESENTED IN TABLE I.

\begin{tabular}{ccccc}
\hline Sensors & $\mathcal{M}_{1}$ & $\mathcal{M}_{2}$ & $\mathcal{M}_{3}$ & $\mathcal{M}_{4}$ \\
\hline \hline \multicolumn{5}{c}{$\mathrm{PM}_{2} \cdot{ }_{5}$} \\
\hline \hline $\mathcal{S}_{1}$ & -0.21 & 0.05 & -0.22 & 0.08 \\
\hline $\mathcal{S}_{2}$ & 0.05 & 0.27 & 0.12 & 0.19 \\
\hline $\mathcal{S}_{3}$ & 0.34 & 0.44 & 0.41 & 0.44 \\
\hline $\mathcal{S}_{4}$ & 0.39 & 0.5 & 0.47 & 0.24 \\
\hline \hline \multicolumn{5}{c}{$\mathrm{CO}_{2}$} \\
\hline \hline $\mathcal{S}_{1}$ & -0.03 & 0.1 & -0.01 & 0.11 \\
\hline $\mathcal{S}_{2}$ & 0.51 & 0.46 & 0.55 & 0.44 \\
\hline $\mathcal{S}_{3}$ & -0.02 & -0.07 & -0.06 & -0.05 \\
\hline $\mathcal{S}_{4}$ & 0.35 & 0.09 & 0.21 & -0.11 \\
\hline \multicolumn{5}{c}{}
\end{tabular}

good correlation between the number of movements and $\mathrm{CO}_{2}$, but the sensors 2 and 4 show linear correlation trend through the coefficient at $r=0.51$ and $r=0.35$, respectively.

In our experiment, the scatter plots in Fig. 4 and Fig. 5 , the correlation coefficients presented in Table II do not provide reasonable correlations between $\left(\mathrm{PM}_{2.5}\right.$ and $\left.\mathrm{CO}_{2}\right)$ and the number of motions due to several reasons. First, the low 
cost sensors used in our experiment do not typically provide extremely accurate results affecting the data recordings. These sensors sometimes may be very sensitive in sensing very low concentration fine particles and/or traced gases. In addition, in our study we performed an uncontrolled experiment. This means that, during the experiment, we did not control the number of people, the location of ventilation, opening and closing the entrance and exit doors as well as the door of the coffee room which all are used several times every day. Moreover, the duration of experimentation would also be another reason that has influenced the results. This means that the data was not collected for a long period of days. Consequently, the uncontrolled experiment has produced noise in the recorded data.

Furthermore, another source of noise would have been because of other unmeasured variables that might influence the concentrations of $\mathrm{PM}_{2.5}$ and $\mathrm{CO}_{2}$ in the working space [17]. For example, the amount of sunlight (e.g. solar radiation) and other traced gases as well as the volatile organic compounds (VOCs) might influence the formation of $\mathrm{PM}_{2.5}$ and $\mathrm{CO}_{2}$. Whereby, this can be considered as a complex chemical and physical process. Therefore, the relationship between these measured and unmeasured variables may also be non-linear.

Indeed, the scatter plot and Pearson correlation coefficient are used for investigating linear correlation between two variables, that is typically very effective for non-complex processes. Non-linear correlation analysis should be performed further to investigate how the measured and unmeasured are interacting [18].

\section{CONCLUSION}

In this paper, we contributed by investigating the feasibility of infrastructure-based indoor motion sensors as a proxy for assessing variations in indoor air quality. We presented results from a feasibility study conducted in a smart office environment that sought to establish a relationship between motion detector measurements and $\mathrm{CO}_{2}$ and $\mathrm{PM}_{2.5}$ concentration. Our results highlighted the relationship between number of movement and $\mathrm{PM}_{2.5}$ concentrations. For $\mathrm{PM}_{2.5}$, a strong relationship can be established. However, for $\mathrm{CO}_{2}$, no clear relationship can be established. Indeed, our results suggest that the formation of $\mathrm{PM}_{2.5}$ and $\mathrm{CO}_{2}$ concentration through movement is complex, due to chemical and physical processes and the impact of other unmeasured variables, e.g., VOCs, the quality of sensors, and characteristics of human activity within the space. We will explore this complex relationship with a larger population of space users in future work.

\section{ACKNOWLEDGEMENTS}

This work is supported by MegaSense program, The City of Helsinki Innovation Fund, the European Union through the Urban Innovative Action Healthy Outdoor Premises for Everyone (project number UIA03-240), and by Helsinki Center for Data Science (HiDATA) program. This work is also partially supported by the Academy of Finland grant 297741.

\section{REFERENCES}

[1] World Health Organization, "Household air pollution and health," May 2018, accessed 2019-03-28. [Online]. Available: https://www.who.int/news-room/fact-sheets/detail/household-airpollution-and-health

[2] J. Zhou, A. Chen, Q. Cao, B. Yang, V. W.-C. Chang, and W. W. Nazaroff, "Particle exposure during the 2013 haze in singapore: Importance of the built environment," Building and Environment, vol. 93, pp. 14-23, 2015.

[3] Z. Peng, W. Deng, and R. Tenorio, "Investigation of indoor air quality and the identification of influential factors at primary schools in the north of china," Sustainability, vol. 9, no. 7, 2017. [Online]. Available: http://www.mdpi.com/2071-1050/9/7/1180

[4] S. Patel, J. Li, A. Pandey, S. Pervez, R. K. Chakrabarty, and P. Biswas, "Spatio-temporal measurement of indoor particulate matter concentrations using a wireless network of low-cost sensors in households using solid fuels," Environmental research, vol. 152, pp. 59-65, 2017.

[5] Y. Zheng, F. Liu, and H.-P. Hsieh, "U-air: When urban air quality inference meets big data," in Proceedings of the 19th ACM SIGKDD International Conference on Knowledge Discovery and Data Mining, ser. KDD '13. New York, NY, USA: ACM, 2013, pp. 1436-1444. [Online]. Available: http://doi.acm.org/10.1145/2487575.2488188

[6] E. Lagerspetz, N. Hossein Motlagh, M. Arbayani Zaidan, P. L. Fung, J. Mineraud, S. Varjonen, M. Siekkinen, P. Nurmi, Y. Matsumi, S. Tarkoma, and T. Hussein, "Megasense: Feasibility of low-cost sensors for pollution hot-spot detection," in 2019 IEEE 17th International Conference on Industrial Informatics (INDIN), Helsinki, Finland, July 2019.

[7] J. Coleman and F. Meggers, "Sensing of indoor air qualitycharacterization of spatial and temporal pollutant evolution through distributed sensing. front," Built Environ, vol. 4, p. 28, 2018.

[8] I. B. Arief-Ang, M. Hamilton, and F. D. Salim, "Rup: Large room utilisation prediction with carbon dioxide sensor," Pervasive and Mobile Computing, vol. 46, pp. 49-72, 2018.

[9] J. Qian, J. Peccia, and A. Ferro, "Walking-induced particle resuspension in indoor environments: A review," Atmospheric Environment, vol. 89, p. 464481, 062014.

[10] Y. Kubota and H. Higuchi, "Aerodynamic particle resuspension due to human foot and model foot motions," Aerosol Science and Technology, vol. 47, no. 2, pp. 208-217, 2013. [Online]. Available: https://doi.org/10.1080/02786826.2012.742486

[11] M. Alshitawi and H. Awbi, "The effect of human movement on the resuspension of airborne particles," in Proceedings of the 12th International Conference on Indoor Air and Climate, Austin, TX, paper ID, vol. 3. Austin, TX: Curran, 01 2011, pp. 1940-1945.

[12] X. Zhang, G. Ahmadi, J. Qian, and A. Ferro, "Particle detachment, resuspension and transport due to human walking in indoor environments," Journal of Adhesion Science and Technology, vol. 22, no. 5-6, pp. 591-621, 2008. [Online]. Available: https://doi.org/10.1163/156856108X305624

[13] A. Benabed and K. Limam, "Resuspension of indoor particles due to human foot motion," Energy Procedia, vol. 139, pp. 242 - 247, 2017, materials \& Energy I (2015). [Online]. Available: http://www.sciencedirect.com/science/article/pii/S187661021735614X

[14] O. Özgr, "An overview of metal oxide semiconducting sensors in electronic nose applications," in 3rd International Symposium on Sustainable Development, Sarajevo, Bosnia and Herzegovina, Oct 2012, pp. 506515.

[15] C. Leys, C. Ley, O. Klein, P. Bernard, and L. Licata, "Detecting outliers: Do not use standard deviation around the mean, use absolute deviation around the median," Journal of Experimental Social Psychology, vol. 49, no. 4, pp. 764-766, 2013

[16] J. Benesty, J. Chen, Y. Huang, and I. Cohen, "Pearson correlation coefficient," in Noise reduction in speech processing. Springer, 2009, pp. $1-4$.

[17] A. Jaribion, S. H. Khajavi, N. H. Motlagh, and J. Holmström, "[wip] a novel method for big data analytics and summarization based on fuzzy similarity measure," in 2018 IEEE 11th Conference on Service-Oriented Computing and Applications (SOCA), Nov 2018, pp. 221-226.

[18] M. A. Zaidan, V. Haapasilta, R. Relan, P. Paasonen, V.-M. Kerminen, H. Junninen, M. Kulmala, and A. S. Foster, "Exploring non-linear associations between atmospheric new-particle formation and ambient variables: a mutual information approach," Atmospheric Chemistry and Physics, vol. 18, no. 17, pp. 12699-12 714, 2018. 